УДК 624.131.1

\author{
А.Н. Богомолов, Ю.И. Олянский, С.И. Шиян, Д.Н. Ушаков \\ Волгоградский государственный университет архитектуры и строительства, \\ Волгоград, Россия

\section{РЕОЛОГИЧЕСКАЯ ХАРАКТЕРИСТИКА САРМАТСКИХ ГЛИН ЦЕНТРАЛЬНОГО ПРЕДКАВКАЗЬЯ И СЕВЕРНОГО ПРИЧЕРНОМОРЬЯ}

\begin{abstract}
Выполнены реологические исследования глин при влажности на пределе текучести. Анализ результатов позволил выделить типы глин, наиболее предрасположенные к образованию оползней течения.

Ключевые слова: сарматская глина, реологическая характеристика, пластическая десормация.
\end{abstract}

A.N. Bogomolov, Yu.I. Olyanskyi, S.I. Shijn, D.N. Ushakov

Volgograd State University of Architecture and Civil Engineering, Volgograd, Russian Federation

\title{
RHEOLOGICAL CHARACTERIZATION OF SURMUT CLAYS CENTRAL CAUCASUS AND NORTHERN BLACK SEA COAST
}

Was study the reological propertys of surmut clays. Distinguish the type of clay fabourable for make lands lide.

Keywords: surmut clay, reological characterization, plastic flow.

Сарматские глины в краевых прогибах юга Русской платформы служат основанием инженерных сооружений на значительной территории Северного Причерноморья и Центрального Предкавказья и часто являются причиной образования на склонах оползней.

Глинистые породы сармата накапливались в Сарматском морском бассейне, восточная часть которого характеризовалась повышенной соленостью воды по сравнению с западной, где происходило разбавление речным стоком с Русской платформы. Вследствие этого на востоке сформировались глинистые породы с более высокой минерализацией порового раствора, чем на западе. 
Различия в химическом составе поровых вод обусловили разную степень агрегатизации грунтовых частиц: на востоке - более высокую, чем на западе, что нашло свое отражение в существенном различии микроагрегатного состава глин обоих регионов при достаточно одинаковом их гранулометрическом составе. Последний свидетельствует об одной площади сноса терригенного материала Русской платформы.

Постгенетические преобразования глинистых пород вследствие залегания их в различных по степени увлажнения климатических зонах совместно с разными условиями осадконакопления обусловили различия в показателях физических свойств глин обоих регионов: на востоке это более влажные, менее плотные сильнопористые отложения, а на западе - прямо наоборот.

Все различия в составе и физических свойствах глин обоих регионов нашли свое отражение в их набухаемости и прочности. Более засоленные глины Центрального Предкавказья, отличающиеся повышенной влажностью, набухают меньше, чем одновозрастные отложения из Северного Причерноморья. Давление набухания первых в среднем на один порядок меньше, чем вторых. Такая же закономерность имеет место и с прочностью, но различия в показателях прочности несколько меньше.

В результате выветривания глинистые породы активно разрушаются и часто образуют плащевидные скопления бесструктурных пород на склонах. С ростом влажности и величины действующих напряжений в скопившихся массах возникают оползневые явления, которые часто можно наблюдать в природных условиях на склонах, сложенных сарматскими глинами. Исследование реологических свойств глинистых пород с нарушенной структурой позволяет прогнозировать их способность к образованию оползней при увлажнении.

Исследования сарматских глин обоих регионов осуществлялись в лаборатории на ротационном вискозиметре Воларовича (РВ-8) по методу установления изменения скорости деформации и эффективной вязкости с ростом действующего напряжения сдвига на образцах нарушенного сложения (пастах) с максимальным размером агрегатов, равным 1 мм при влажности, соответствующей пределу текучести.

Для изученных глин были получены реологические кривые $d \varepsilon \mid d t=f(P)$, значения условного статического предела, текучести $P_{K-1}$, условно-динамического предела текучести $P_{K-2}$ и предела прочности 
$P_{m}$. Кроме того, получены кривые изменения эффективной вязкости в зависимости от изменения напряжения сдвига $\eta=f(P)$, определены значения вязкости близ условного предела текучести $\eta_{P_{K-1},}$ и наименьшей вязкости нарушений структуры $\eta_{m}$. Вискозиметр позволил получить обратную ветвь реологической кривой - ветвь восстановления вязкости (структуры) по мере уменьшения действующего напряжения.

Анализ показателей реологических свойств (таблица) кривых был сделан на образцах сарматских глин Северного Причерноморья и Центрального Предкавказья. Он показал, что все изученные глины относятся к различным типам по реологическому поведению по классификации И.М. Горьковой [2]. Основными являются: структурно-вязкие, тиксотронные бингамовские, пластичные шведовские и эластичнопластично-вязкие.

Основные характеристики показателей реологических свойств сарматских глин Северного Причерноморья и Центрального Предкавказья

\begin{tabular}{|l|c|c|c|c|}
\hline \multirow{2}{*}{ Показатель } & \multicolumn{3}{|c|}{ Регионально-генгетические типы глин } \\
\cline { 2 - 5 } & $\begin{array}{c}\text { Верхний } \\
\text { сармат } \\
N=17\end{array}$ & $\begin{array}{c}\text { Средний } \\
\text { сармат } \\
N=15\end{array}$ & $\begin{array}{c}\text { Средний } \\
\text { сармат } \\
N=6\end{array}$ & $\begin{array}{c}\text { Нижний } \\
\text { сармат } \\
N=60\end{array}$ \\
\cline { 2 - 5 } & Северное Причерноморье & Центральное Предкавказье \\
\hline$P_{K-1}$, кПа & $\frac{1,7-3,8}{2,85}$ & $\frac{1,0-3,2}{2,42}$ & $\frac{1,6-1,9}{1,72}$ & $\frac{1,1-4,1}{2,64}$ \\
\hline$P_{K-2}$, кПа & $\frac{3,7-7,3}{5,41}$ & $\frac{2,8-6,6}{4,88}$ & $\frac{4,4-6,0}{5,05}$ & $\frac{4,3-10,7}{7,18}$ \\
\hline$P_{m}$, кПа & $\frac{4,6-8,7}{6,64}$ & $\frac{3,9-7,4}{5,92}$ & $\frac{5,6-8,1}{6,63}$ & $\frac{6,4-11,9}{9,23}$ \\
\hline$\eta_{P_{K-1,}, 10^{3} П а \cdot с}$ & $\frac{0,12-5,20}{1,72}$ & $\frac{0,30-12,3}{1,69}$ & $\frac{3,4-4,0}{3,7}$ & $\frac{2,3-8,8}{4,3}$ \\
\hline$\eta_{m,}$ Па·с & $\frac{9,3-27,7}{19,70}$ & $\frac{1,6-21,9}{16,87}$ & $\frac{150-214}{176}$ & $\frac{142-617}{220}$ \\
\hline$\eta_{P_{K-1,}} / \eta_{m}$ & $\frac{60-802}{357}$ & $\frac{25-719}{546}$ & $\frac{187-268}{212}$ & $\frac{73-535}{219}$ \\
\hline
\end{tabular}

Примечание: в числителе пределы колебания, в знаменателе - средние.

Структурно-вязкий тип характерен для образцов глинистых пород, содержащих повышенное количество дисперсных частиц, какими являются глины верхнего сармата и реже - среднего сармата Северного 
Причерноморья. В нарушенном состоянии эти образцы обладают способностью к медленному течению типа ползучести практически без нарушения структуры (рис. 1).

обр. 29

обр. 168

обр. 248
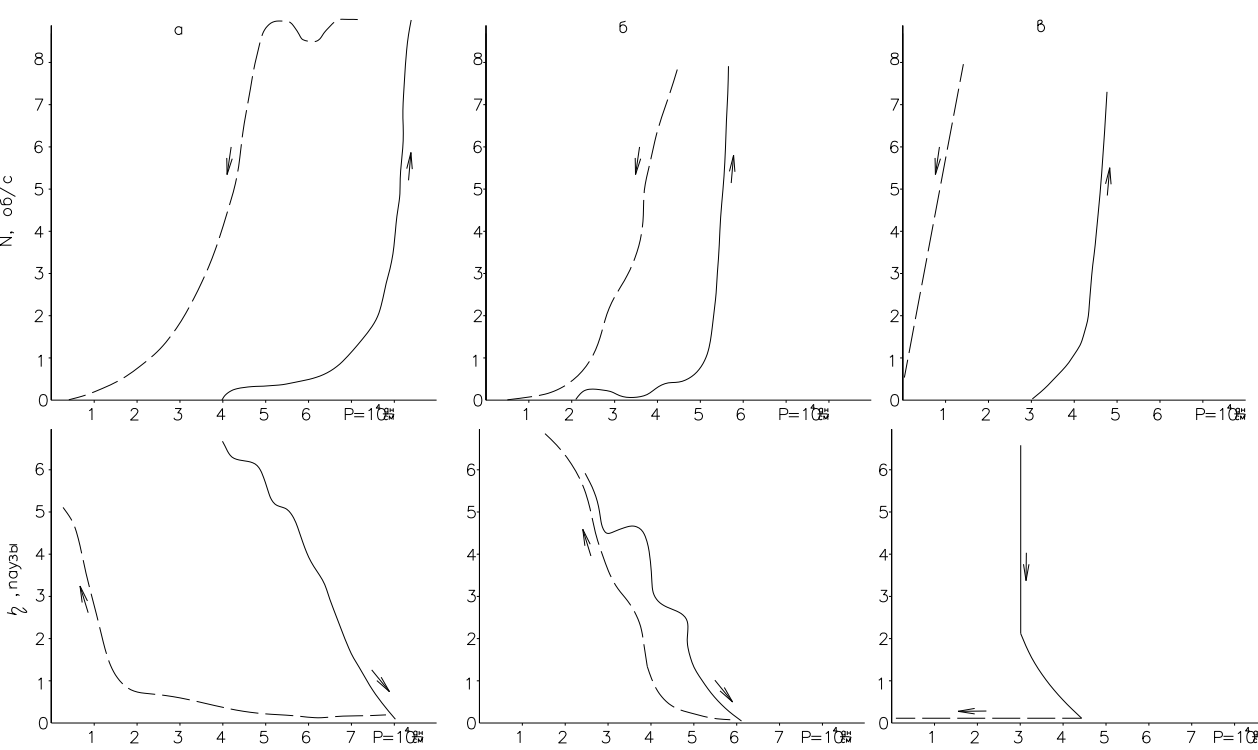

обр. 171
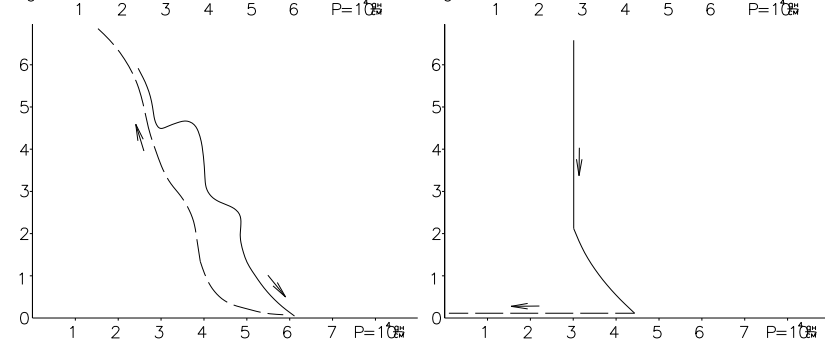

обр. 149

обр. 100
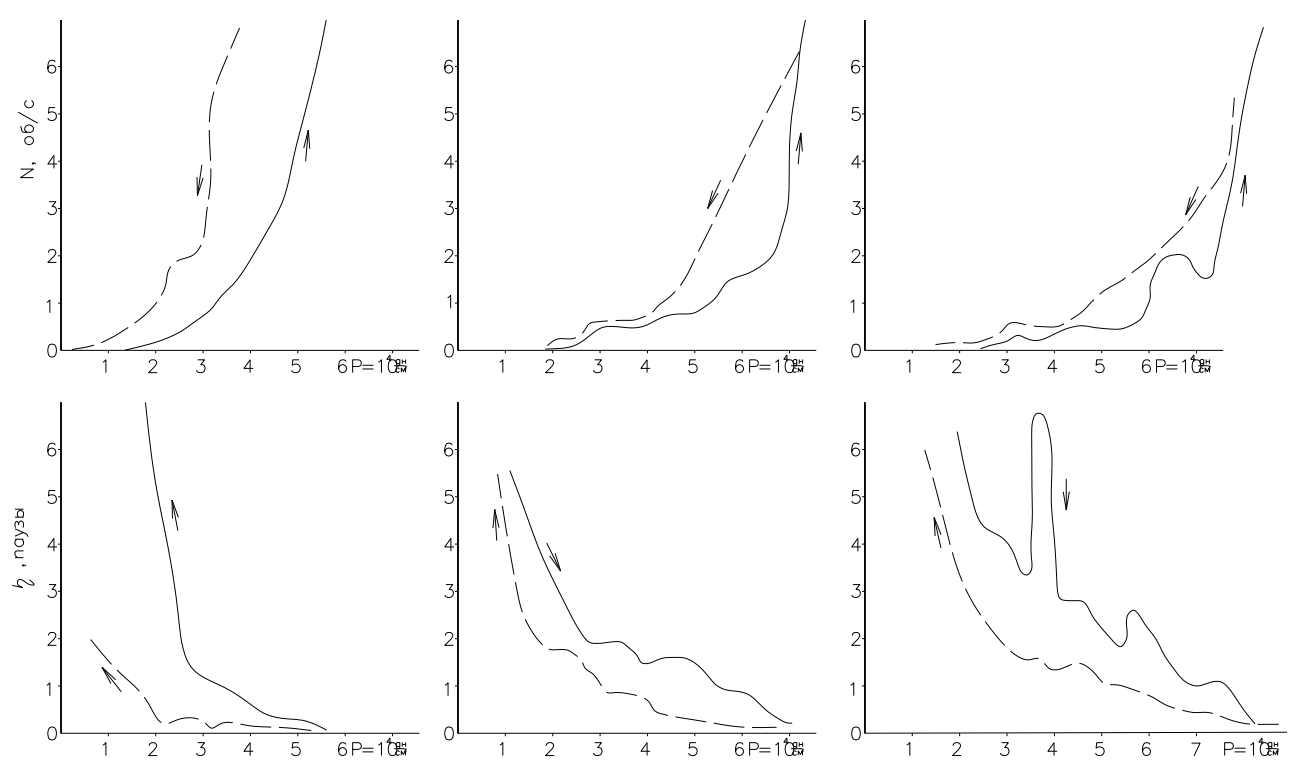

Рис. 1. Реологические кривые образцов сарматских глин Северного Причерноморья с нарушенной структурой [4]: $a-$ бингамовский и структурно-вязкий типы; $\sigma$ - шведовский тип 
После снятия напряжения глины остаются в разжиженном состоянии и обладают плывунными свойствами.

На рис. $1,2[3,4,5]$ представлены типичные реологические кривые и кривые зависимости эффективной вязкости от действующего напряжения.

обр. $1, \mathrm{~N}_{1} \mathrm{~S}_{1}$

обр. $2, \mathrm{~N}_{1} \mathrm{~S}_{2}$

обр. $3, \mathrm{~N}_{1} \mathrm{~S}_{2}$

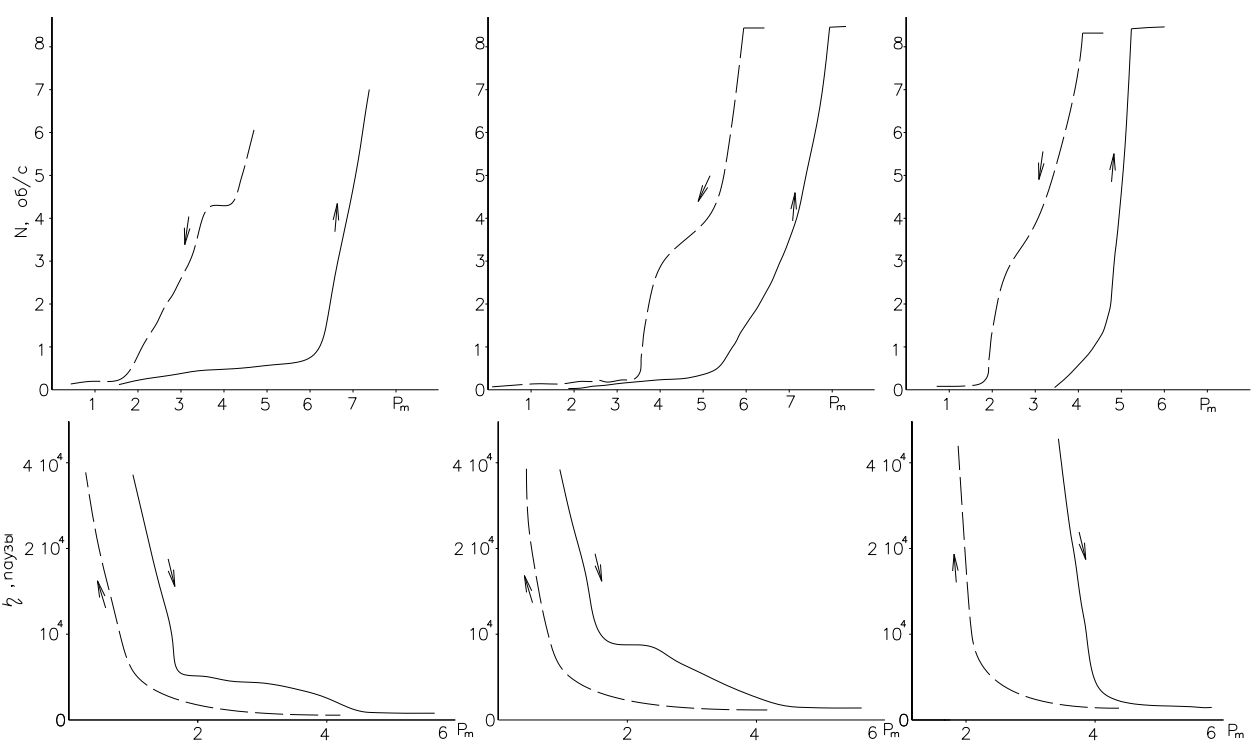

Рис. 2. Реологические кривые образцов сарматских глин

Центрального Предкавказья [3]

Тиксотропный бингамовский тип наиболее распространен среди всех изученных регионально-генетических типов глинистых пород, характеризующихся влажностью предела текучести $W_{L}=0,40-0,55$ и числом пластичности $J p=0,22-0,28$. Характерной особенностью этих пород является твердообразный облик реологических кривых (рис. 1, $a$, б), обуславливающий большой гистерезис в восстановлении вязкости только при полном снятии напряжения. Средние значения условно статического предела текучести для таких пород составляют 2,5 и 2,79 кПа, условного динамического предела текучести - 5,01 и 5,06 кПа соответственно для глин с влажностью предела текучести равной 0,4-0,5 и 0,5-0,6.

Пластичный шведовский тип наиболее характерен для образцов с пониженной пластичностью $\left(W_{L}=0,29-0,40, J p=0,14-0,20\right)$, какими являются в большей мере глины среднего сармата, содержащие прослои обломочного материала. Реологические кривые этих пород характеризуются менее твердообразным обликом и меньшим гистерезисом 
в восстановлении вязкости (рис. 2). Средние значения условного статического и динамического пределов текучести составляют 0,33 и 4,99 кПа. (Ю.И. Олянский, Е.В. Щекочихина [5]).

Характерной особенностью некоторых реологических кривых, изображенных на рис. 1, являются слабо выраженные пределы текучести и прочности за счет эффекта дилатансии, проявляющегося в виде бугров и пиков на отрезках кривых, соответствующих течению со шведовской пластичной вязкостью. Это объясняется дилатантным упрочнением образца вследствие нагромождения песчаных зерен с ростом действующего напряжения. Явление дилатансии наиболее наглядно проявляется у образцов с пониженным значением числа пластичности и за счет содержания в дисперсной массе пасты микроагрегатов со стабилизационными контактами, что приближает эти глины по реологическому поведению к суглинистым дисперсно-песчаным породам.

Все образцы Центрального Предкавказья имеют хорошо выраженный условный статистический предел текучести $P_{K-1}$. (см. таблица). На всех реологических кривых (см. рис. 2) отчетливо выражен прямолинейный участок наибольшей пластической вязкости, ограниченный напряжениями. Разрушение, образовавшейся структуры при напряжениях происходит более или менее постепенно, а далее за бингамовским пределом текучести $P_{K-2}$ структура пасты активно разрушается, она становится высокоподвижной и течет с наименьшей пластической вязкостью. Прямолинейный участок отчетливо выделяется на всех кривых.

После предварительного разрушения структуры вязкость по мере убыли напряжения восстанавливается по-разному: как правило, тиксотропность характеризуется петлей гистерезиса, достаточно большой для большинства образцов. У многих образцов вязкость восстанавливается в области текучести.

По характеру деформационного поведения паст сарматские глины Северного Причерноморья и Центрального Предкавказья можно отнести к группе тонкодисперсных пород, переходных от пластичновязких к упругопластичновязким разновидностям. К этой группе отнесены мелководные илы Черного моря, глубоководные новоэвксинские илы, пасты бентонита и сантонского мергеля при влажности ниже границы текучести. Согласно предложенной И.М. Горьковой схеме [1] зависимость деформационных особенностей пород от комплекса классификационных показателей, сарматские глины относятся к группам 
высокодисперсных и смешанных пород со стабилизационными, пластифицировано-коагуляционными, коагуляционно-цементацион-ными и цементационными структурными связями, средней плотностью водонасыщенных, слабой и средней степени уплотнения, средней и высокой степени литификации.

\section{Библиографический список}

1. Горькова И.М. Теоретические основы оценки осадочных пород в инженерно-геологических целях. - М.: Наука, 1966. - 136 с.

2. Горькова И.М. Принципы комплексной оценки и инженерногеологическая классификация глинистых и лессовых пород // Научные труды ПНИИИС. - М., 1971. - Т. 4. - С 4-53.

3. Монюшко А. М. Инженерно-геологическая оценка сарматских глин. - М.: Наука, 1974. - 135 с.

4. Монюшко А.М. Олянский Ю.И. Инженерно-геологические особенности сармат-меотических глин Молдовы. - Кишинев: Штиинца, 1991. - $172 \mathrm{c}$.

5. Олянский Ю.И., Щекочихина Е.В. Реологическая оценка сарматских глин как основа регионального прогноза оползней течения // Вестник ВолгГАСУ. Строительство и архитектура. - Волгоград: Изд-во ВолгГАСУ, 2009. - Вып. 14 (33). - С. 13-16.

\section{References}

1. Gorkova I.M. Teoreticheskie osnovy otsenki osadochnykh porod v inzhenerno-geologicheskikh tselyakh [Theoretical framework for the assessment of sediment in geotechnical purposes]. Moscow: Nauka, 1966. $136 \mathrm{~s}$.

2. Gorkova I. M. Printsipy kompleksnoy otsenki i inzhenernogeologicheskaya klassifikatsiya glinistykh i lessovykh porod [Integrated assessment and engineering-geological classification of clay and loess]. Nauchnye trudy PNIIIS. Moscow, 1971. vol. 4. pp. 4-53.

3. Monyushko A.M. Inzhenerno-geologicheskaya otsenka sarmatskikh glin [Engineering geological assessment sarmatian clays]. Moscow: Nauka, 1974. $135 \mathrm{~s}$.

4. Monyushko A.M. Olyanskiy Yu.I. Inzhenerno-geologicheskie osobennosti sarmat-meoticheskikh glin Moldovy [Geotechnical features sarmatian-meotic clay Moldova]. Kishinev: Shtiintsa, 1991. $172 \mathrm{s.}$

5. Olyanskiy Yu.I., Shchekochikhina E.V. Reologicheskaya otsenka sarmatskikh glin kak osnova regional'nogo prognoza opolzney techeniya 
[Rheological evaluation of Sarmat clays as the basis for regional forecast of liquefaction landslides]. Vestnik VolgGASU, Building and Architecture, 2009. no. 14 (33). pp. 13-16.

\section{Об авторах}

Богомолов Александр Николаевич (Волгоград, Россия) - доктор технических наук, профессор, проректор по научной работе, заведующий кафедрой «Гидротехнические и земляные сооружения» Волгоградского государственного архитектурно-строительного университета; e-mail: banzaritcyn@mail.ru

Олянский Юрий Иванович (Волгоград, Россия) - доктор геолого-минералогических наук, профессор кафедры «Гидротехнические и земляные сооружения» Волгоградского государственного архитектурно-строительного университета.

Шиян Сергей Иванович (Волгоград, Россия) - кандиат технических наук, доцент, докторант кафедры «Гидротехнические и земляные сооружения» Волгоградского государственного архитектурно-строительного университета.

Ушаков Дмитрий Николаевич (Волгоград, Россия) - аспирант кафедры «Гидротехнические и земляные сооружения» Волгоградского государственного архитектурно-строительного университета.

\section{About the autors}

Bogomolov Aleksandr Nikolaevich (Volgograd, Russian Federation) - Doctor of Technical, Sciences Professor, vice rector of the science, the Head of Hydraulic and Earthwork Structures Department, Volgograd State University of Architecture and Civil Engineering; e-mail: banzaritcyn@mail.ru

Olyansky Yurij Ivanovich (Volgograd, Russian Federation) - Doctor geol.-mineral., Professor of «Hydraulic and earthworks», Volgograd State University of Architecture and Civil Engineering.

Shiyan Sergej Ivanovich (Volgograd, Russian Federation) - Ph. D. in Technical Sciences, Associate Professor of Doctoral Candidate «Hydraulic and earthworks», Volgograd State University of Architecture and Civil Engineering.

Ushakov Dmitriy Nikolaevich (Volgograd, Russian Federation) Doctoral Student of Hydraulic and Earthwork Structures Department, Volgograd State University of Architecture and Civil Engineering. 
Получено 21.03.2014 